\title{
Investigating Facial Animation Production Through Artistic Inquiry
}

\author{
Robin Sloan ${ }^{1}$, Brian Robinson ${ }^{1}$, Malcolm Cook $^{2}$ \\ Division of Computer Arts ${ }^{1}$, Division of Psychology ${ }^{2}$ \\ University of Abertay Dundee \\ Dundee, UK \\ r.sloan@abertay.ac.uk, b.robinson@abertay.ac.uk,m.cook@abertay.ac.uk
}

\begin{abstract}
Studies into dynamic facial expressions tend to make use of experimental methods based on objectively manipulated stimuli. New techniques for displaying increasingly realistic facial movement and methods of measuring observer responses are typical of computer animation and psychology facial expression research. However, few projects focus on the artistic nature of performance production. Instead, most concentrate on the naturalistic appearance of posed or acted expressions. In this paper, the authors discuss a method for exploring the creative process of emotional facial expression animation, and ask whether anything can be learned about authentic dynamic expressions through artistic inquiry.
\end{abstract}

Keywords-component; animation; character; emotional expression; facial expression; practice-led research

\section{INTRODUCTION}

Believable characters in film, TV, and games are becoming increasingly important to the entertainment industries. As graphical quality improves, the need for movement quality to improve has escalated. In games, for example, authentic animated character performances can compliment game play and boost narrative immersion. In film, inauthentic movement can potentially intensify the effect of 'uncanny valley'. Audiences might be repelled by characters whose movements - while almost believable - do not match their expectations of dynamic human appearance. Performance capture technology can accurately reproduce acted performance for film - for example Beowulf [4] and The Polar Express [26]. Facial motion capture is being utilized in games as well. Image Metrics [14], for example, provide capture services for creating believable animation for games and film.

In spite of technological advances, however, performance capture cannot currently be used to produce fully interactive characters. Performance capture is based on unchanging acted performances, whereas game characters must be able to adapt in real time. One way to produce authentic interactive characters would be to procedurally animate the performances, in the same way that packages like Endorphin [24] can be used to create procedural physical animation. But to achieve this, a better understanding of what makes an animated performance believable is needed.

One aspect of performance that has received considerable attention is emotional facial expression. Research into how emotions are expressed and how observers perceive facial expressions has informed artistic practice and animation training [9][17] but, as yet, not much is known about the intricacies of perceptually believable expression performance, in particular as regards the timing, sequence, and duration of facial cues. Investigation into traditional animation production and audience perception of emotional expression 'choreography' could lead to advanced training guides for character animation, and also lay the ground work for believable real-time animation of interactive characters.

To investigate the creative production of expressional performances, however, it is necessary to consider the process of traditional animation production as a vehicle for research. This requires a degree of formal research through artistic inquiry. In Section II, the authors introduce a practice-led facial animation project, entitled 'Emotional Avatars'. Related research and an overview of how knowledge can be generated through the intuitive practice of character animation are covered in Section III. The method of inquiry through traditional animation practice is discussed in Section IV.

\section{Emotional AVATARs Project}

'Emotional Avatars' is an interdisciplinary research project which aims to explore the potential for 'choreographing' authentic emotional facial expression animations. Unlike similar projects - which often attempt to identify how best to present dynamic expressions in order to maximise observer recognition - the goal of 'Emotional Avatars' is to investigate the creative practice of iterative animation production. If more is known about why animator's choose to construct dynamic expressions in certain ways, then it might be possible to identify the building blocks of authentic dynamic facial expressions. This knowledge could then form the basis for authentic interactive expressions - something that rigid performance capture cannot currently achieve, since the very nature of performance capture implies the uninterrupted and noninteractive replication of acted performance.

To do this, a practice-based methodology has been developed which structures the iterative creative production of facial animation. Using this methodology, the lead author - acting as a practitioner-researcher - will create a range of animations to fit specific criteria. Through reflective practice, the researchers will attempt to determine the overall logicality, practicality, and reliability of emotional expression choreographies. 


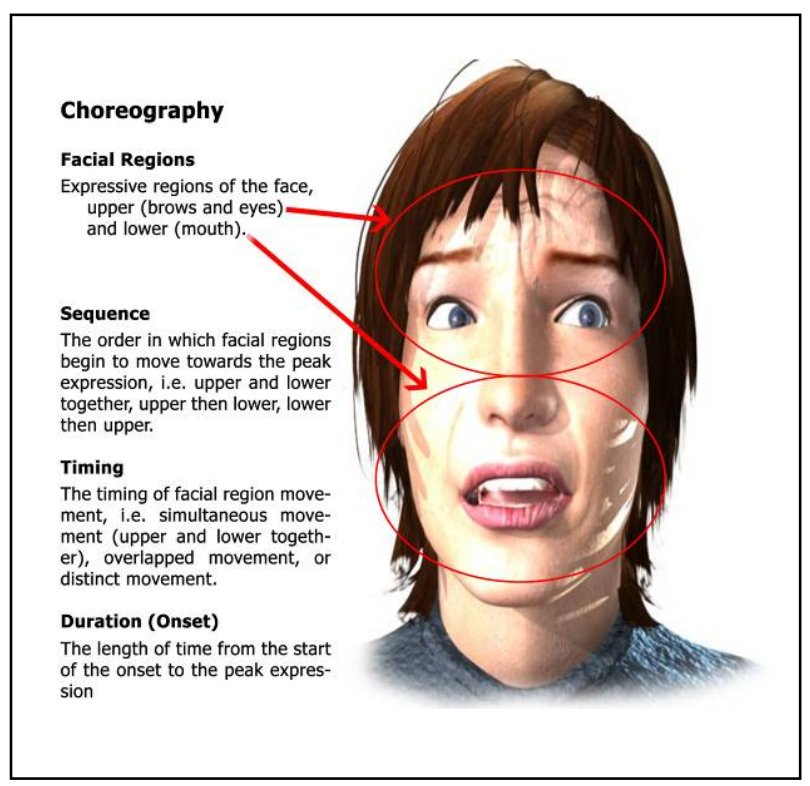

Figure 1. The two regions of the face independently manipulated by the practitioner-researcher, and the three conditions of choreography which determine how the regions should be manipulated.

Emotional expression choreography is defined by three conditions; the sequence, timing, and duration of upper and lower facial movements (see Figure 1). For example, for the current study, the practitioner-researcher iteratively produced a range of emotional expression animations to fit the criteria of the sequence condition. The six universal expressions (happy, sad, anger, fear, disgust, and surprise) were animated using the three levels of the sequence condition (upper and lower face move together, upper face moves first, lower face moves first). Figure 2 shows an example of two sequences being used to manipulate the appearance of an emotional expression transition.

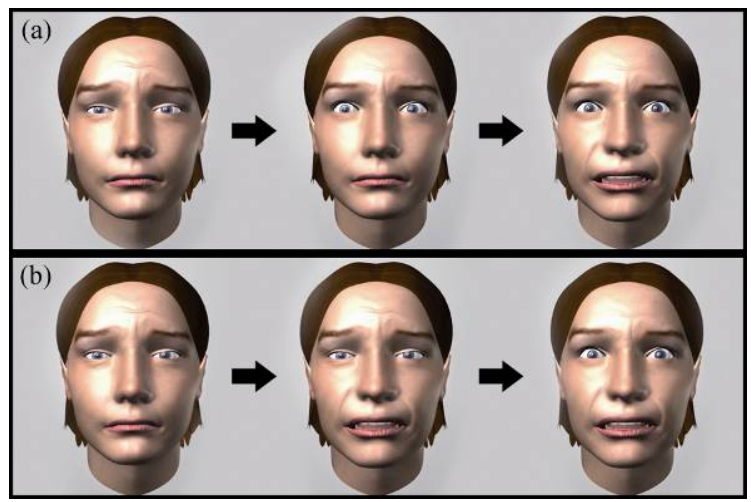

Figure 2. Example of sadness into fear animation when the sequence condition is manipulated. (a) shows the second level - upper face leads the lower face. (b) shows the third level - lower face leads the upper face.
TABLE I. SUBJECTIVE CONSIDERATIONS USED BY THE PRACTITIONER

\begin{tabular}{|l|l|l|l|}
\hline $\begin{array}{c}\text { Quality } \\
\text { Measures }\end{array}$ & Good & Moderate & Poor \\
\hline Logicality & Intuitive & $\begin{array}{l}\text { Somewhat } \\
\text { intuitive }\end{array}$ & $\begin{array}{l}\text { Counter- } \\
\text { intuitive }\end{array}$ \\
\hline Practicality & $\begin{array}{l}\text { Easy to } \\
\text { use }\end{array}$ & Tricky to use & $\begin{array}{l}\text { Difficult to } \\
\text { use }\end{array}$ \\
\hline Reliability & $\begin{array}{l}\text { Clear and } \\
\text { authentic } \\
\text { animation }\end{array}$ & $\begin{array}{l}\text { Problems with } \\
\text { clarity or } \\
\text { authenticity }\end{array}$ & $\begin{array}{l}\text { Not clear or } \\
\text { authentic } \\
\text { animation }\end{array}$ \\
\hline
\end{tabular}

The aim of the current research is to ascertain whether certain choreographies of motion based on the sequence condition are acceptable for emotional expression animation. Through reflective animation practice, the practitionerresearcher will contemplate three practice-related subjective considerations (see Table 1.). The practitioner will first determine how logical the choreographies are - a logical choreography being one which the practitioner finds intuitive, while an illogical choreography is counter-intuitive. The second consideration is practicality. Practical choreographies are easy and quick to use, while impractical choreographies require more time and work. Finally, the practitioner will consider the reliability of the final animations - in other words, how representative they are of the intended emotion, how clear that emotion is, and how authentic the animation looks.

For the duration of the project, the practitioner-researcher will create iterations of animation to fit the conditions of choreography, drawing upon animation training and experience, reference materials, and existing research into facial expressions.

\section{RELATED RESEARCH}

In terms of facial expression research, a range of psychology and computing projects have explored expression production and perception. Expression research can be dated back to Darwin [6], but most current researchers consider the Facial Action Coding System (FACS) [8] to be the first major step towards a scientific understanding of facial expressions. FACS has informed a number of animation and computing projects [1][3][15]. Studies into facial perception have identified universal expressions [7], the core expressions being happiness, sadness, anger, fear, disgust, and surprise.

To create animations of expressions, blending (or morphing) is often used in computing [19][27] and psychology [23] research. While this is an effective way to simplify the transition between states, blends do not necessarily consider how the temporal subtleties of a performance can affect authenticity.

Research has shown that expressions might have typical movements in terms of the sequence of facial regions over time. Smiles, for instance, might often start with lower face movement, with upper face movement occurring towards the end of the expression [22]. The temporal unfolding of facial regions has not been tested thoroughly with the universal 
expressions, however, and the effect of sequence manipulation on perceived believability has not been investigated. Furthermore, studies of naturally occurring expressions do not take into account the creative performance of nuanced facial expressions.

Sequential movements made up of distinct facial actions over time have been theorized [34], although the effect on observer perception is not certain. Studies applying this theory to computer generated faces may yet produce evidence that specific sequences of movement appear more authentic than simultaneous movement [21]. However, this approach also neglects the creative aspect of performance, concentrating on the theorized natural appearance of expressions over time.

The importance of facial regions [12][25] and actions [2] to emotional states have been examined. Additionally, spatiotemporal facial attributes have been manipulated and tested [33]. However, while most of these projects focus on the significance of spatial or temporal attributes to perception, none consider the artistic reasoning behind spatiotemporal facial animation choices.

It would appear that most current research into emotional facial expression ultimately concerns the perceptual qualities of the expressions, and that expressions generated or examined are typically based on naturalistic appearances. While computer animation studies systematically alter dynamic expressions and develop new techniques for creating animation, the focus seems to be on what observers can recognize and how authentic expression animations can be produced, rather than why particular configurations of expression animations might have an effect on audiences. Perception research is of course important, but then so too is the performance driven practice of the actor or animator. In order to explore the artistic reasoning behind facial animation, it is necessary to adopt a different approach to research - one that does not concentrate solely on the expansion of technical knowledge or make use of strictly objective methods of assessing observer perception. If the process of creative expression animation can be considered a means of generating new knowledge, then the performative nature of the expressions can be investigated.

\section{A. Performative Research}

While the majority of related projects concern objective research into natural expressions and observer perception, the artistic production of animation appears to be overlooked. The depiction of facial expression in art - e.g., in painting, film, and animation - is usually based on natural truth, but draws heavily upon certain artistic truths. For example, the principles of animation [32] suggest unnatural events, such as exaggeration and anticipation. It could be argued that the goal of the animator is to create an effective imitation - rather than strict replication - of life.

Objective researchers can rigorously record or generate expression videos, and results may be easy to replicate. However, a subjective epistemology - allowing interaction with the research material through practice - is arguably a better approach to examine the intuitive practice of character animation. From this perspective, the researcher becomes a practitioner-researcher. As Gray and Malins [11] explain, this approach is quite different to positivist research:

'In the role of the 'practitioner-researcher', subjectivity, involvement, reflexivity is acknowledged; the interaction of the researcher with the research material is recognized. Knowledge is negotiated - inter-subjective, context bound, and is a result of personal construction. Research material may not necessarily be replicated, but can be made accessible, communicated and understood.” (p21)

Haseman [13] expands on this, arguing for a third research paradigm, alongside the traditional quantitative and qualitative approaches. He describes the third paradigm as "performative research" - the performing of action in order to carry out creative practice-based research. Bolt [5] too recognizes this paradigm, suggesting that "we come to know the world theoretically only after we have come to understand it through handling".

The performative research paradigm is useful for structuring the practice-led approach of the 'Emotional Avatars' project. That is not to say that traditional methods and objective experimentation are redundant. The development of a mixed-methods methodology is crucial to the investigation of expression choreography. However, for investigating animation production from an artistic perspective, structured methods for carrying out performative research seem appropriate.

In his Ph.D thesis, Fenton [10] adopts a reflectivepractice approach to creative research, making use of a number of tools appropriate to his discipline (theatre). In particular, his use of structured inquiry is interesting. Some of the tools used by Fenton for investigating the creative process are described in more detail by Gray and Malins [11]. For instance, Fenton's reflective journal can be seen as an extension of the work of Schon [28] and Kolb [18], and journaling can be used as a tool for data collection through reflective practice. The creative process is also given a structure, which Haseman [13] likens to the "enquiry cycle of action research". This cycle is described as: planning a change, acting and observing the process and consequences of a change, reflecting on these processes and consequences, planning a new change, and so on.

For the purposes of structured and systematic investigation of facial expression animation, the inquiry cycle method - applied through the use of tools like journals - is quite appropriate. It allows for discipline-specific tools (such as animation software) to be used as part of goalorientated and iterative creative production. As such, the inquiry cycle has been adopted as the primary method of generating knowledge through creative facial animation practice for the 'Emotional Avatars' project.

\section{METHOD}

The current research examines the choreography of neutral into emotional expression animations, where the sequence of regional movement is the condition of choreography that is manipulated (see Figure 1). 


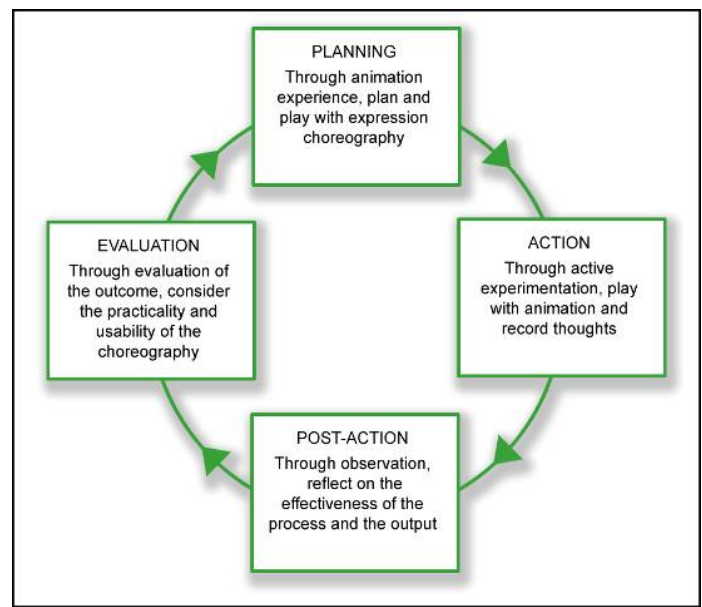

Figure 3. Inquiry cycle for iterative animation production

\section{A. Inquiry Cycle Method}

To explore the question of whether choreographed emotional facial expressions can be of use to animators, iterations of animation were produced using a modified inquiry cycle (See Figure 3). At this stage of the research, the focus was on practice rather than perception, although practitioner observation of animation is an important aspect of the process.

The first stage of the cycle was Planning. At this stage, the practitioner considered contributing factors and experimented with expression manipulation using the tools of traditional animation practices. Contributing factors primarily consisted of existing research into facial expression generation and perception [7][12][22][25][33], the artistic depiction of facial expressions [9][17], and traditional animation guides [32][35]. In particular, the images of peak emotional expressions collected by Ekman and Friesen [7] were useful when the facial shapes were being constructed. Art-based resources offered insight into the creative depiction of expressions, which can be based on nature but strengthened through artistic truth. The principles of animation were also an important resource during planning. For facial expression animation planning, it was particularly important to consider timing, anticipation, staging, follow through and overlapping action [32].

Through the study of scientific and artistic references and creative experimentation, the aim of the practitionerresearcher was to plan and adapt emotional expression animations to fit the criteria of the sequence condition. All thoughts on how logical and practical a sequence might be and how the planned animation might yield an authentic animation - were recorded using the tools described in the next section.

The next stage of the cycle was Action - the active practice of creating and testing of animation. At this stage the practitioner-researcher quickly and efficiently produced animation based on the planning stage. Using computer animation software, animations were blocked out, refined, rearranged, and manipulated in real time, providing instant feedback for consideration.
The Post-action stage was used to reflect on the creative process undertaken during the Action stage of the cycle. The practice related considerations (see Table I) were explored by reflecting on the actions undertaken by the practitioner (was the choreography logical and practical) and through observation of the result (was the final animation reliable). Although occurring after a period of practice, the Post-action stage of the inquiry cycle was distinct from detailed reflection-on-practice, since the Post-action stage was essentially a quick look back on what was just achieved before moving on to evaluation and a new plan of action. Detailed reflection-on-practice, as Smith [31] points out, requires space and time. Detailed reflection-on-practice tools will be used as part of the project but are not discussed in this paper.

In the final stage of the cycle, the practitioner-researcher Evaluated the knowledge generated through the current iteration of production. This involved linking what was known about expression appearance and production, animation techniques, planning according to choreography constraints, the personal practice of animation under those constraints, and the personal observation of output. In particular, the practitioner looked to identify potential alterations that could correct errors or alleviate problems. This was effectively the pre-planning stage, before the cycle was repeated and new iterations of animation using the same condition were produced

The inquiry cycle provides a framework for iterative creative art production and reflection-in-practice, but a range of tools must also be employed in order to create the artwork, record findings, and analyze the work.

\section{B. Tools for Production, Recording, and Analysis}

For producing concept work and creating animation, a sketchbook (see Figure 4) and the 3D animation package Maya 2008 [20] were used respectively. The former was used to plan out animations and record thoughts on the use of particular spatial or temporal configurations. For the animation of sequentially choreographed emotional facial expressions, each sequence was planned and explored both visually and with annotations.

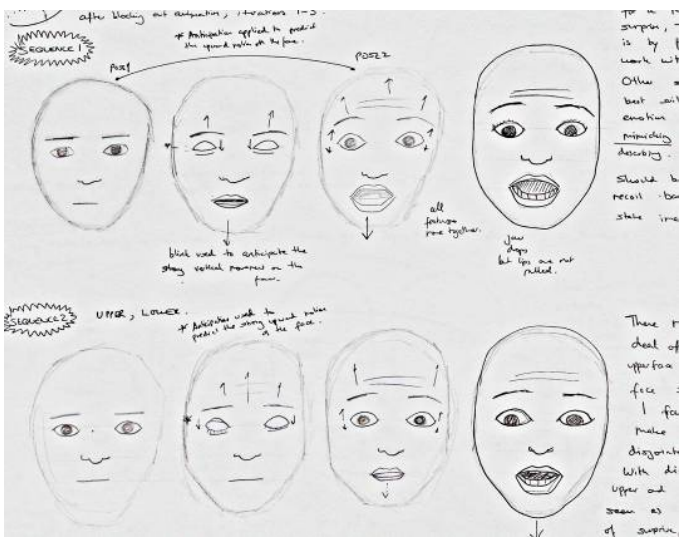

Figure 4. Example of animation planning in a page from the sketchbook, including sketches, annotations, and additional text. 
Every sequence of movement was laid out visually through the sketching of key poses and breakdowns. Sketches were annotated to demonstrate the planned timing and strength of subtle movement within the face. When influences from reference materials and resources had an effect on the planning, details were noted beside the relevant drawings. For example, anticipation (a principle of animation) was applied in the planning of surprise expressions through the use of a blink immediately before the upward motion of the upper lids and brows.

The real-time feedback of animating using Maya allowed for highly efficient reflection-in-action. A record of creative experimentation with the software was easy to keep, since a new file could be saved for each iteration of animation. From Maya, videos of animation were rendered. These videos were used by the practitioner as a tool for assessing the potential reliability of the sequences. Observation of the videos allowed for a non-interactive personal interpretation of the animation produced, helping the practitioner to determine the quality of the output, i.e., whether it was representative of the intended emotion and suitably authentic.

Through successive iterations of the inquiry cycle, journaling was used to record the thoughts of the practitioner. The journal was carefully structured to highlight each stage of the cycle, for consecutive iterations and for each choreography. The deliberate structuring of the journal made data reduction easier at the conclusion of the study, and ultimately helped to steer the analysis of the work.

The artwork and records generated in the journal, sketchbook, and animation files were compiled in a multimedia matrix (see Figure 5). This allowed the practitioner-researcher to compare the work and clarify the subjective reflection on the process and output, in terms of the logicality, practicality, and reliability of sequence choreographies. The subjective conclusions of the practitioner-researcher based on the comparison of artwork and records in the matrix are summarized in Table II.

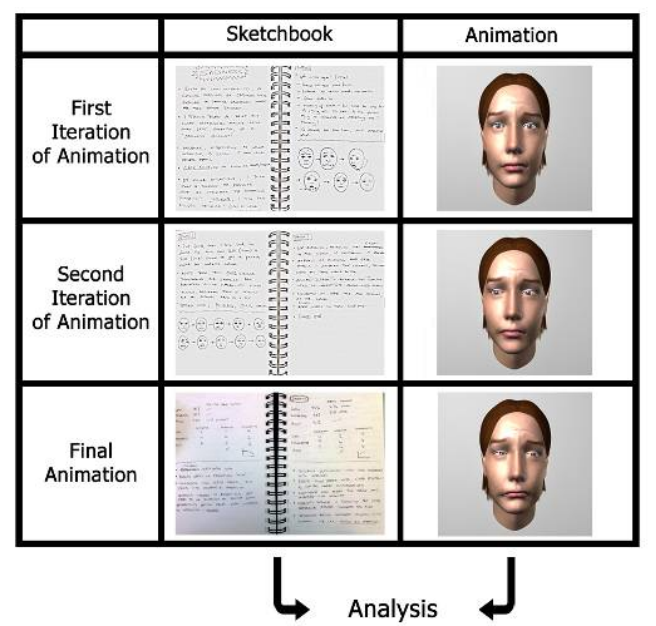

Figure 5. The development over time of sketches, animation files, and journal entries are displayed in a multimedia matrix

\section{Results}

Firstly, for animations of happiness, the sequence of lower into upper face movement was deemed the most logical, practical, and reliable. This matched up with reference material, which indicated a natural appearance of a smile before squinting in the eyes. Simultaneous movement of facial regions was workable, although the sudden appearance of a full happy face perhaps lent itself better to a reactionary expression of joy. Upper into lower face motion was a poor sequence for all three considerations.

For sadness, the practitioner-researcher had more trouble discriminating between sequences. Simultaneous movement and lower into upper face movement resulted in reliable animation, although both were less logical and practical than upper into lower face movement. This may be because the contorted mouth shape in the peak expression of sadness conveyed an intense feeling of sadness, and therefore it seemed more appropriate for this to develop after initial signs of sadness in the upper face.

Anger expressions seemed to work best with upper into lower face movement, since the lowering of the brow (which is present in all expressions of anger) manifested itself early on. Simultaneous movement worked well, although the practitioner showed a tendency to begin with upper face movement, indicating that - logically - the upper face should lead. When movement started with the lower face, the end result was potentially reliable, but the process of producing the animation according to the criteria was arduous.

Simultaneous movement and upper into lower face movement proved to be the better sequences for fear animation. The former worked well for all considerations, although fell short logically. This may be because the lower face was useful as a means of expressing an intensification of fear. The latter was more effective, as fear could be portrayed in the upper face before the lower face conveyed an increase in the emotion. Leading with lower face movement failed on all three considerations. The initial static upper face did not work well for this particular emotion.

For disgust animations, all three sequences received moderate to good results across the three considerations. Of these, the sequence of lower into upper face movement appeared to be the best overall, as the distinctive sneer of the expression developed early on in the animation. This seemed logical and yielded a reliable animation fairly easily. Simultaneous movement developed into a reactionary expression of disgust as, logically, the eyes should be delayed in order to intensify the expression as the emotion develops. The sequence starting with upper face movement was practical to work with, but did not seem as logical as the reverse sequence and also produced an animation that observers might confuse with anger (since the brow lowers before evidence of disgust is shown in the lower face).

Finally, animations of surprise clearly worked best with simultaneous movement. When the upper face moved before the lower face, the outcome was somewhat reliable, but the logicality and practicality of the sequence were poor. All three considerations received poor results for the sequence of lower into upper face movement. 
TABLE II. RESULTS OF INQUIRY CYCLE - WHERE SEQUENCE 1 IS SIMULTANEOUS MOVEMENT, SEQUENCE 2 UPPER INTO LOWER FACE MOVEMENT, AND SEQUENCE 3 LOWER INTO UPPER FACE MOVEMENT

\begin{tabular}{|l|l|l|l|l|}
\hline Emotion & Seq. & Logical & Practical & Reliable \\
\hline Happiness & 1 & Moderate & Moderate & Moderate \\
\hline Happiness & 2 & Poor & Poor & Moderate \\
\hline Happiness & 3 & Good & Good & Good \\
\hline Sadness & 1 & Moderate & Moderate & Good \\
\hline Sadness & 2 & Good & Good & Good \\
\hline Sadness & 3 & Moderate & Moderate & Good \\
\hline Anger & 1 & Moderate & Good & Good \\
\hline Anger & 2 & Good & Good & Good \\
\hline Anger & 3 & Poor & Poor & Moderate \\
\hline Fear & 1 & Moderate & Good & Good \\
\hline Fear & 2 & Good & Good & Good \\
\hline Fear & 3 & Poor & Poor & Poor \\
\hline Disgust & 1 & Moderate & Good & Good \\
\hline Disgust & 2 & Moderate & Good & Moderate \\
\hline Disgust & 3 & Good & Good & Good \\
\hline Surprise & 1 & Good & Good & Good \\
\hline Surprise & 2 & Poor & Poor & Moderate \\
\hline Surprise & 3 & Poor & Poor & Poor \\
\hline
\end{tabular}

\section{CONCLUSION AND FURTHER WORK}

The iterative production of facial animation (with reflective-practice) has revealed a subjective interpretation of what is and isn't effective for a particular set of emotional expression choreographies. As discussed earlier, the interpretation of the practitioner-researcher - developed through reflective personal practice - is valid as an outcome of formal arts research, providing that the approach is clearly structured and that the research material is accessible and understood. However, the application of additional analyses and methods can be used to support and verify the findings of the practitioner-researcher.

Firstly, tools for carrying out detailed reflection-onaction are appropriate for examining the work produced. The data reducing matrix approach - described in the previous section - helped the researcher to compare the various animations produced, and to identify which choreographies he deemed logical, practical, and reliable. John's [16] Method of Structured Reflection (MSR) - also used by Fenton [10] in his research - will be used by the researcher to reflect on the creative process more carefully, leading to a better understanding of the appropriateness of the choreography concept. Furthermore, a supervisory review tailored to the context of the project - will be completed by both the supervisor and the practitioner-researcher as they review the final animation together [30]. The review will aim to structure and record a period of reflection that can be likened to the relationship between director and animator. As well as examining the practitioner's use of shape deformation and timing within the face, other aspects of the animation will be considered - for instance, whether regional movements look voluntary or involuntary, and whether the final animation resembles the intended emotional state.
The output of the inquiry cycle - animations of expressions based on sequence - will be tested on observers under controlled conditions using an experimental method [29][30]. This will allow for a degree of quantitative research, using observers to verify the conclusions of the practitioner. Statistical analysis will be used to determine whether the effect of sequence on perception is significant

Finally, collaboration with animation students [30] will take place in the autumn of 2009. Students will adopt the inquiry cycle method for facial animation production, producing iterations of animation and rating the logicality, practicality and reliability of choreographies. The method of student collaboration will lead to an assessment of the intersubjectivity of choreography - in other words, whether a consensus can be reached regarding particular choreographies of sequence, timing, and duration. This will add further weight to the subjective interpretation of the usability of emotional expression choreographies.

\section{SUMMARY}

In this paper, the authors introduced the practice-led research project 'Emotional Avatars', and discussed the use of one artistic method for investigating the production of emotional facial expression animation. The inquiry cycle method for iterative animation production was based on notions of performative research (research through artistic practice, with a subjective epistemology). The overall methodology of the 'Emotional Avatars' project incorporates methods of reflective creative practice, controlled experimentation, and collaboration.

Ultimately, the authors aim to discover whether more can be learned about facial animation production by approaching the subject from an artistic perspective. Artistic research could compliment quantitative and qualitative facial expression research, and lay the foundations for the development of real-time characters with authentic, dynamic facial expression.

Future studies will look at the other choreography conditions (timing and duration) and also at emotional expression transitions (from one emotion to another, e.g., anger into fear). Other artistic and scientific methods for exploring the concept of emotional expression choreography will be used. This includes the experimental method for assessing objective observer perception [29], and peer collaboration for evaluating inter-subjective artistic insight [30].

\section{REFERENCES}

[1] Arya, A. and DiPaola, S. (2006). 'Socially communicative characters for interactive applications'. The 14th International Conference in Central Europe on Computer Graphics, Visualization and Computer Vision, Plzen, Czech Republic

[2] Arya, A., DiPaola, S. and Parush, A. (2009). 'Perceptually valid facial expressions for character-based applications'. International Journal of Computer Game Technology. (Accepted for publication 2009).

[3] Battista, S., Casalino, F. and Lande, C. (1999). 'MPEG-4: a multimedia standard for the third millennium, part 1'. IEEE MultiMedia. 6(4): 74-83. IEEE Press, 1999.

[4] Beowulf. (2007). [Film]. Directed by Robert Zemeckis. USA: ImageMovers 
[5] Bolt, B. (2004). Art beyond representation: the performative power of the image. London and New York: I.B. Tauris.

[6] Darwin, C. (1872). The expression of emotions in men and animals. London: John Murray.

[7] Ekman, P. and Friesen, W.V. (1975). Unmasking the face. New Jersey: Prentice-Hall

[8] Ekman P. and Friesen, W.V. (1977). Manual for the facial action coding system. Palo Alto: Consulting Psychologists Press

[9] Faigin, G. (1990). The artist's complete guide to facial expression. USA: Watson-Guptil Publications.

[10] Fenton, D.R. (2007). Unstable acts : a practitioner's case study of the poetics of postdramatic theatre and intermediality. Ph.D. Brisbane: Queensland University of Technology.

[11] Gray, C. and Malins, J. (2004). Visualising research: a guide to the research process in art and design. Aldershot: Ashgate Publishing Limited. Aldershot, England.

[12] Griesser, R.T., Cunningham, D.W., Wallraven, C. and Bulthoff, H.H. (2007). 'Psychological investigation of facial expressions using computer animated faces'. Symposium on Applied Perception in Graphics and Visualisation, Tubingen, Germany: ACM Press.

[13] Haseman, B. (2007). Rupture and recognition: identifying the performative research paradigm. In E. Barret and B. Bolt, eds. Practice as research: approaches to creative arts enquiry. London: I.B. Tauris \& Co Ltd. Ch. 11.

[14] Image Metrics. (2008). Superior facial animation. Simplified. [Online]. Available at: http://www.image-metrics.com. [Accessed February 12th 2009].

[15] Institute of Animation, Visual Effects and Digital Postproduction. (2006). Research \& development at the Institute of Animation. [Online]. Available at: http://research.animationinstitut.de/ [accessed 10 Dec 2007]

[16] Johns, C. (1995). Achieving effective work as professional activity. In J. Schober and S. Hinchliff, eds. Towards Advanced Nursing Practic. Edward Arnold. Ch. 11.

[17] Kalwick, D.J. (2006). Animating facial features and expressions. Boston: Charles River Media.

[18] Kolb, D.A. (1984). Experiential Learning: experience as the source of learning and development New Jersey: Prentice-Hall

[19] Lin, D.T. and Huang, H. (1999). 'Facial expression morphing and animation with local warping methods'. In Proceedings of the 10th international Conference on Image Analysis and Processing, September 27-29, 1999.

[20] Maya 2008 (2008). [Computer Software]. Autodesk.

[21] Malatesta, L., Raouzaiou, A., Karpouzis, K. and Kollias, S.D. (2009). Towards modeling embodied conversational agent character profiles using appraisal theory predictions in expression synthesis. Appl. Intell. 30(1): 58-64.

[22] Messinger D, Fogel A. and Dickson K.L. (1999). What's in a smile? Dev Psychol. 35:701-708.

[23] Montagne, B., Kessels, R.P.C., Frigerio, E., de Haan, E.H.F. and Perret, D.I. (2005). 'Sex differences in the perception of affective facial expressions: do men really lack emotional sensitivity?'. Cognitive Processing. 6(2): 136-141.

[24] NaturalMotion. (2006). Endorphin: dynamic motion synthesis. [Online]. Available at: http://www.naturalmotion.com/endorphin.htm. [Accessed 3rd July 2009].

[25] Nusseck, M., Cunningham, D.W., Wallraven, C. and Bülthoff, H.H. (2008). 'The contribution of different facial regions to the recognition of conversational expressions'. Journal of Vision, 8(8):1, 1-23

[26] The Polar Expess. (2004). [Film]. Directed by Robert Zemeckis. USA: Castle Rock Entertainment.

[27] Pyun, H., Kim, Y., Chae, W., Kang, H.W. and Shin, S.Y. (2003). 'An example-based approach for facial expression cloning'. In Proceedings of the 2003 ACM Siggraph/Eurographics Symposium on Computer Animation. San Diego, CA, Jul 26-27, 2003.

[28] Schon, D. (1983). The Reflective Practitioner: How professionals think in action. London: Temple Smith.

[29] Sloan, R.J.S., Cook, M. and Robinson, B. (2009). 'Considerations for believable emotional facial expression animation'. 2nd International Conference on Visualization, Barcelona, Spain.

[30] Sloan, R.J.S., Robinson, B. and Cook, M. (2009). 'A practice-led methodology for researching the creative production of emotional facial expression animation'. SAND conference. Swansea, UK 23-27 November 2009. (Submitted for publication June 2009).

[31] Smith, M.K. (2001). 'Donald Schön: learning, reflection and change'. the encyclopedia of informal education. [Online]. (Updated June $18^{\text {th }}$ 2009). Available at: www.infed.org/thinkers/et-schon.htm. [Accessed June 20th 2009].

[32] Thomas, F. and Johnston, O. (1981). The illusion of life: Disney animation. New York: Disney Editions.

[33] Wallraven, C., Breidt, M., Cunningham, D.W. and Bulthoff, H.H. (2008). 'Evaluating the perceptual realism of animated facial expressions'. ACM Transactions on Applied Perception. 4(4): 1-20.

[34] Wehrle, T., Kaiser, S., Schmidt, S. and Schere, K.R. (2000) 'Studying the dynamics of emotional expression using synthesized facial muscle movements'. Journal of Personality and Social Psychology, 78(1), 105-119.

[35] Williams, R. (2001). The animator's survival kit: a working manual of methods, principles and formulas for computer, stop-motion, games and classical animators. London: Faber and Faber. 